\title{
LINAC Stereotactic Radiosurgery for brain arteriovenous malformation: a single institutional experience from Saudi Arabia
}

\author{
Muhammad M Fareed ${ }^{1 *}$, Abdullah A Amro ${ }^{2 \dagger}$, Yasser Bayoumi ${ }^{3+}$, Yasser I Orz ${ }^{4 \dagger}$, Mutahir Tunio ${ }^{5 \dagger}$, Ahmad Maklad ${ }^{6 \dagger}$ and Khalid Riaz ${ }^{7 \dagger}$ \\ *Correspondence: fareedmohsin@ymail.com \\ 'These authors contributed equally to this work. \\ ${ }^{1}$ Assistant Consultant, Radiation Oncology, King Fahad Medical City, Riyadh, Saudi Arabia. \\ ${ }^{2}$ Consultant Radiation Oncologist, King Fahad Medical City, Riyadh, Saudi Arabia. \\ ${ }^{3}$ Associate Professor $\mathrm{NCl}$, Cairo University Cairo, Egypt. \\ ${ }^{4}$ Consultant Neurosurgeon National Neurosciences Institute, King Fahad Medical City, Riyadh, Saudi Arabia. \\ ${ }^{5}$ Assistant Consultant, Radiation Oncology, King Fahad Medical City, Riyadh, Saudi Arabia. \\ ${ }^{6}$ Lecturer of Clinical Oncology, Sohag University, Sohag, Egypt. \\ ${ }^{7}$ Resident Radiation Oncology, King Fahad Medical City, Riyadh, Saudi Arabia.
}

\begin{abstract}
Background: Linear accelerator (LINAC) based radiosurgery for a brain arteriovenous malformation (bAVM) is replacing gamma knife radiosurgery. We present clinical outcome, obliteration rates and predictor factors of treatment success following LINAC radiosurgery for bAVM which is not much addressed subject in Middle East.

Methods: 13 patients who underwent LINAC radiosurgery for brain arteriovenous malformations from November 2008 to November 2011 in our radiation oncology department were retrospectively analyzed. Recollection of demographic data, AVM and treatment characteristics along with clinical and radiographic follow up information was done by reviewing the electronic data base.

Results: All thirteen patients underwent stereotactic radiosurgery by linear accelerator based treatment delivery system (BrainLab) over three years. These included 7 males and 6 females, with median age of 22 years. Intracranial hemorrhage was a presenting feature in 7 (54 \%) of patients. Prior embolization was done in 10 (77\%) patients with 7 patients having more than once undergone this procedure. The location of AVM was superficial in $9(70 \%)$ and deep in brain in $4(30 \%)$ patients. The mean AVM score was 0.97 with 3 patients having AVM score $\geq 1$ with mean Spetzler-Martin grade of 2.7 and 8 (62\%) patients having grade 3 or more. Median follow up was 30 months. Mean dose delivered was $21.7 \mathrm{~Gy}$ in single fraction. Complete obliteration of AVM nidus was achieved in $9(70 \%)$ patients while 4 patients $(30 \%)$ had partial obliteration. Six patients (67 \%) achieved complete obliteration among 9 who had AVM score of less than 1 . Post radiosurgery neurological deficit occurred in only one patient in form of right temporal field loss.

Conclusions: Linear accelerator based radiosurgery is promising treatment option for brain AVMs in majority of cases with reasonable adverse effect profile.
\end{abstract}

Keywords: Linear accelerator, stereotactic radiosurgery, brain arteriovenous malformations, embolization

\section{Background}

Cerebral arteriovenous malformations (AVMs) are abnormal connections between the arteries and veins, with poorly formed blood vessels that shunt blood directly from the arterial circulation to the venous system bypassing the capillary network. The high pressures and flow rates in AVM vessels combined with poor construction of the abnormal shunting vessel walls make them vulnerable to rupture and intracranial hemorrhage [1]. Brain AVMs are congenital, but symptoms usually do not appear until the second decade of life. They commonly present with brain hemorrhage, but neurological deficits, seizures and headaches may also occur. The gold standard for diagnosing AVM was conventional angiography in the recent past. However, computed tomography and magnetic resonance angiography are now the first-line diagnostic tools for AVMs [2].
AVMs can occur in the entire central nervous system with a predilection of the supratentorial intracranial compartment. Observation, endovascular embolization, surgical excision and radiosurgery are the main options for management. Based on the characteristics of the lesion, each of these can be used individually or combined as multimodal therapy [3]. Microsurgical resection of a cerebral AVM allows for an immediate therapeutic cure whereas stereotactic radiosurgery (SRS) provides an alternative for inoperable or high-risk lesions that require treatment [4]. Radiosurgery is thought to reduce the risk of hemorrhage in AVMs over the course of 2 to 3 years by obliterating the nidus of abnormal vasculature. Depending on the lesion volume, dose of radiation and the pattern of vascular supply and drainage, success in treating AVMs is variable [5].

The role of radiosurgery as a treatment for arteriovenous malformations is particularly aimed at reducing intracranial

(C) 2013 Fareed et al; licensee Herbert Publications Ltd. This is an Open Access article distributed under the terms of Creative Commons Attribution License (http://creativecommons.org/licenses/by/3.0). This permits unrestricted use, distribution, and reproduction in any medium, provided the original work is properly cited. 
Fareed et al. Neuroscience Discovery 2013,

bleeding due to rupture. Predictive factors for radiosurgery's good results and tolerance include size of nidus, anatomical localization of AVM, prior bleeding or embolization and distributed dose distribution [6]. Although most studies present results of gamma-knife treatment dealing with radiosurgery for cerebral arteriovenous malformations, linear accelerated based radiosurgery is becoming increasingly popular. Much uncertainty still exists about the rationale of combined endovascular and radiosurgical treatment [7]. Stereotactic radiosurgery uses a single fraction high dose radiation while stereotactic radiotherapy uses multifractionated lower dose focused radiation. Our lessons from LINAC precision radiation therapy uphold its value as a promising and effective tool in treating a range of nervous system pathologies [8].

The purpose of this study is to describe our experience in the use of linear accelerator based radiosurgery (RS) for patients with brain arteriovenous malformations (AVMs) in our institute.

\section{Methods}

This retrospective analysis was performed for all patients with brain AVMs treated with SRS in our department. Between November 2008 and December 2011, a total of 13 patients underwent this procedure. All charts were reviewed for collection of demographic data and treatment characteristics. Pretreatment evaluation consisted of complete history and physical including neurological examination, MRI / MRA scan of brain, Angiogram of cerebral vasculature, Complete blood count, Liver function tests and renal profile.

Initial assessment was done for suitability for SRS in relation to location of the nidus, size of the nidus, arterial supply, and medical suitability for DSA. All cases were evaluated by neuroradiologists, neurosurgeons, and radiation oncologists prior to treatment. Patients selected for SRS had AVMs of $<3.5 \mathrm{~cm}$ nidus, located in eloquent/critical area of the brain with a high probability of a neurological deficit in the event of bleeding and with surgical interventions. After an informed consent, patients were scheduled for SRS. A planning MRI neuronavigator scan was mandatory in all cases 1-2 days prior to SRS in which axial postcontrast MRI sections were obtained with $3 \mathrm{~mm}$ slice thickness with no interslice gap at the equalsize matrix ( $256 \times 256)$ and transferred to SRS planning workstation for future fusion. Patients were instructed to get admitted as an inpatient one night before the procedure to be properly investigated, evaluated and counseled prior to the procedure. On the day of SRS procedure, a stereotactic rigid frame was fixed over the skull bone after application of local anesthesia at the site of appropriate pins. CT simulation was done for all patients after immobilizing them in supine position with stereotactic frame. Patient was than to be sent to angiography suite for cerebral angiogram. The nidus with its feeding arteries was identified in the filling phase and marked as the target. A lot of time and effort was spent on consultation with the interventional radiologists for identifying the target for the nidus, and all sets of DSA and imaging were reviewed in detail. Proper position and location of the AVM was marked by primary investigator keeping in consideration the images of MRI, Angiogram and CT simulation. Patients underwent SRS using micromultileaf collimators delivering multiple noncoplanar fixed fields. Treatment planning was done with a stereotactic system (BrainLab, Germany), which provided 26 pairs of mMLC leaves. The projected leaf width at the isocentre ranges from 3 to $5 \mathrm{~mm}$ giving field sizes ranging from $0 \times 0 \mathrm{~cm}^{2}$ to $10 \times 10 \mathrm{~cm}^{2}$. In the BrainLab workstation CT scan, MRI and DSA images were fused manually. The accuracy of fusion was verified before planning. The nidus and organs at risk (OARs) such as pituitary hypothalamic axis, brain stem, eye, lens, optic apparatus, and normal brain were contoured (Figure2). Site of the nidus, nidus volume, nidus shape, and proximity to critical structures was considered during planning. A suitable dose in range of 15-22 Grays in a single fraction was prescribed for all patients. The plan and prescription dose were finalized by using the Flickinger's model of probability of normal tissue toxicity. Highest possible dose was prescribed keeping the risk of normal tissue toxicity probability below $5 \%$. Usually, 7-12 isocentric noncoplanar beams were used for planning. A strict quality assurance program was implemented prior to SRS including Lutz's test for isocentric accuracy before starting treatment.

The final plan had to be executed after being finally reviewed and approved by primary radiation oncologist (Figure1 and 3). After radiation dose delivery, stereotactic frame was to be removed and patient to be discharged home on analgesics (as needed).

\section{Results}

Stereotactic frame was fixed, and DSA was performed in all 13 patients of AVM planned for SRS. Mean age was 22 years (range 17 - 50 years); these included 7 males and 6 females. Intracranial hemorrhage as shown on CT scan brain was a presenting feature in $7(54 \%)$ of patients. 3 (23\%) patients presented with epilepsy. Prior embolization using Onyx was done in 10 (77\%) patients with large AVMs and of whom 7 patients having more than once undergone this procedure. The location of AVM was superficial in 9 (70\%) and deep in brain in 4 (30\%) patients. The mean AVM score was 0.97 with 3 patients having AVM score $\geq 1$ with mean Spetzler-Martin grade of 2.7 and 8 (62\%) patients having grade 3 or more. (AVM score $=(0.1 \mathrm{X}$ AVM volume in $\mathrm{ml}+0.02 \mathrm{X}$ age in years + 0.3 X AVM location); AVM location: $0=$ frontal $/$ temporal; 1 = parietal/occipital/intraventricular/ cerebellar/ callosal; 2 = basal ganglia / thalamus / brain stem). Median follow up was 30 months. Mean dose delivered was $21.7 \mathrm{~Gy}$ in single fraction. Complete obliteration of AVM nidus was achieved in 9 (70\%) patients while 4 patients 

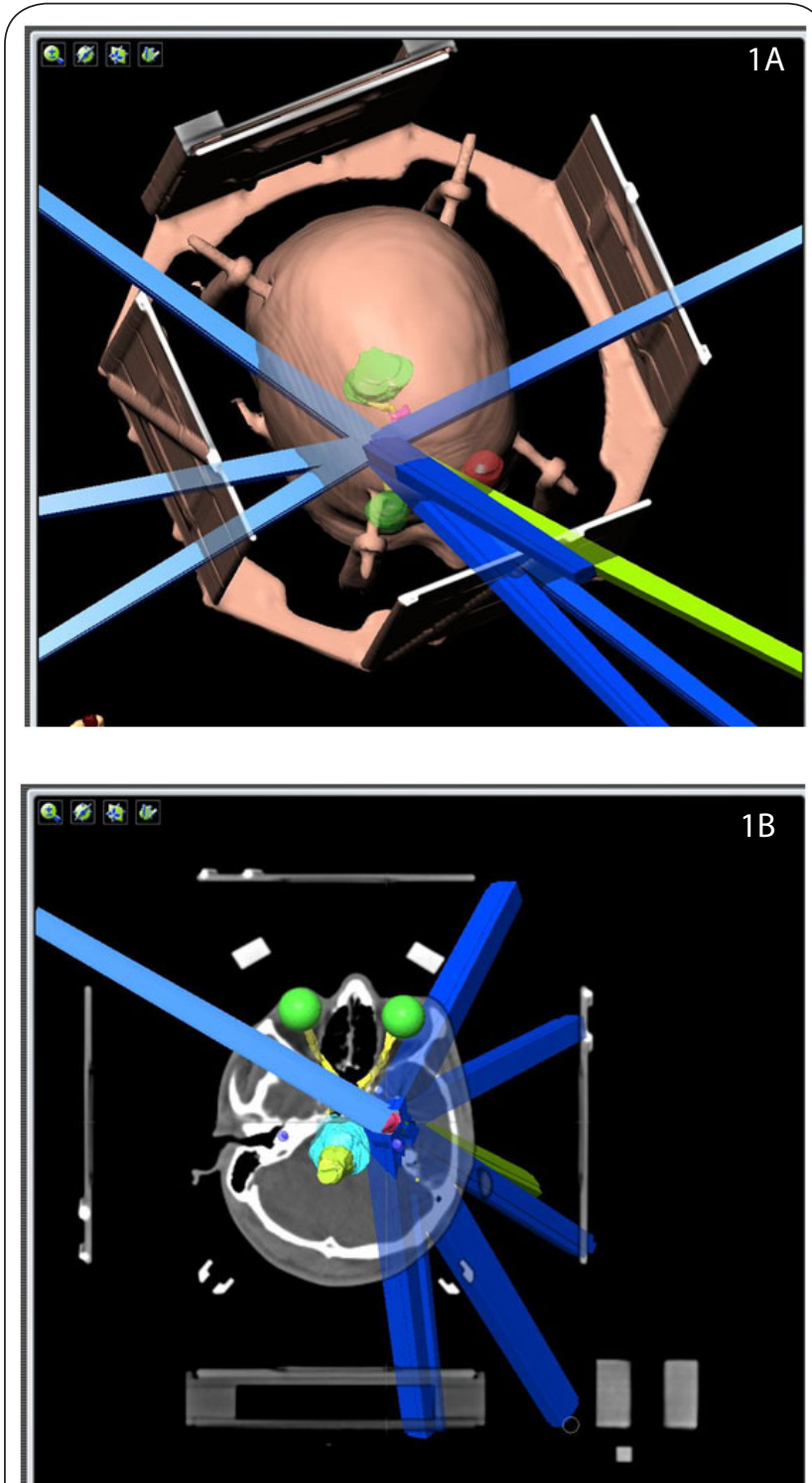

Figure 1. A. Beam's eye view of incident beams. B. Axial view showing beams targeting AVM in left frontal region.

(30\%) had partial obliteration. Six patients (67\%) achieved complete obliteration among 9 who had AVM score of less than 1. Post radiosurgery neurological deficit occurred in only one patient in form of right temporal field loss. The mean number of beams used was 9 (range 7-12). The mean nidus volume was $2.32 \mathrm{cc}$ (range $0.7-4 \mathrm{cc}$ ). The mean prescribed maximum dose was 21.7 Gy (SD 1.95, range 15-22 Gy).Mean dose to brain stem, optic chiasm and optic nerves was 3.40Gy (range $0.11-12.2 \mathrm{~Gy}$ ), 0.55 Gy (range $0.04-2.66$ ), and 0.41 Gy (range 0.01-2.66 Gy), respectively. There was no dose attenuation effect by prior Onyx embolization after radiosurgery. No other patients had symptomatic permanent sequelae related to SRS. All patients are leading an active and functional life. Patients

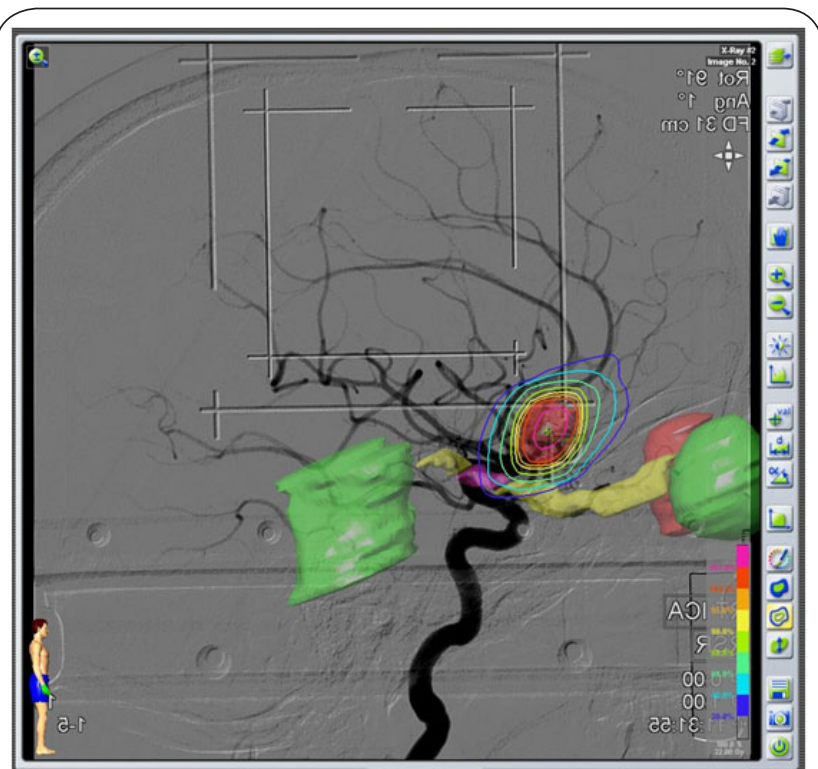

Figure 2. Angiogram showing AVM nidus and feeding vessels. Normal structures including brain stem, optic chiasm, optic nerves and eyes are shown.

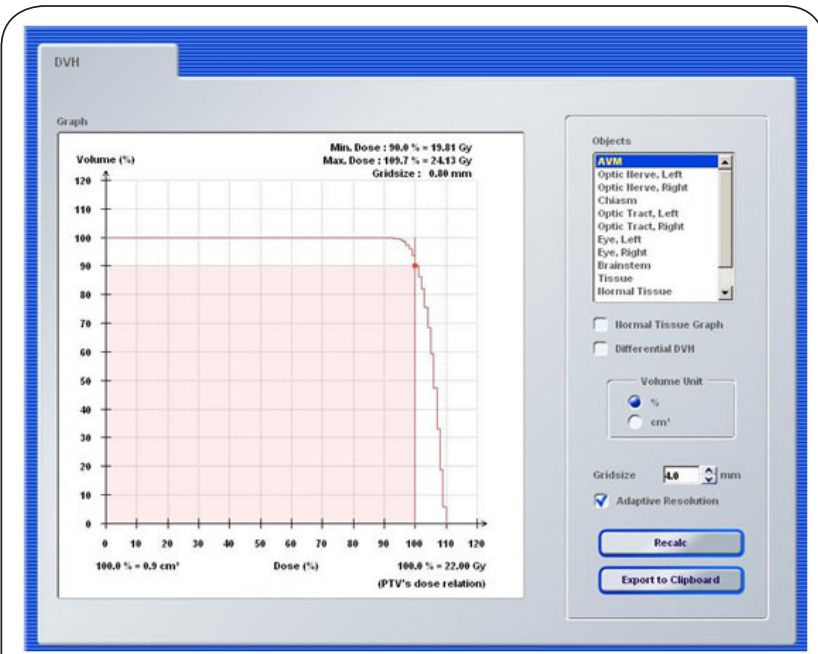

Figure 3. DVH showing relationship of dose to volume.

and treatment characteristics are summarized in Table 1.

\section{Discussion}

Cerebral AVMs are developmental malformations of the intracranial arteriovenous system. Usually they are asymptomatic but when symptomatic present mainly with headache and seizures. Because of their fragile walls and tendency for rupture, the major complication is bleeding. The annual rate of hemorrhage from AVMs is $2-4 \%$ while the lifetime risk is about $40 \%$. There is a higher risk of subsequent bleeding up to $6 \%$ after the first episode of bleeding.Interestingly, smaller AVMs bleed more often than larger ones due to higher blood flow turbulence.However, spontaneous regression may occur in smaller AVMs [9]. 
Fareed et al. Neuroscience Discovery 2013,

http://www.hoajonline.com/journals/pdf/2052-6946-1-1.pdf

doi: $10.7243 / 2052-6946-1-1$

Table 1. Patients and treatment characteristics.

\begin{tabular}{|c|c|}
\hline Variables & $\mathrm{N}(\%)$ \\
\hline Age at presentation & 22 yrs (Range: $17-50)$ \\
\hline $\begin{array}{l}\text { Gender } \\
\text { Male } \\
\text { Female }\end{array}$ & $\begin{array}{l}7(54 \%) \\
6(46 \%)\end{array}$ \\
\hline $\begin{array}{l}\text { Hemorrhage at presentatio } \\
\text { Yes } \\
\text { No }\end{array}$ & $\begin{array}{l}7(54 \%) \\
6(46 \%)\end{array}$ \\
\hline $\begin{array}{l}\text { Seizures at Presentation } \\
\text { Yes } \\
\text { No }\end{array}$ & $\begin{array}{l}3(23 \%) \\
10(77 \%)\end{array}$ \\
\hline $\begin{array}{l}\text { Times Embolization done } \\
\text { None } \\
\text { Once } \\
\text { Twice } \\
\text { Thrice }\end{array}$ & $\begin{array}{l}3(23 \%) \\
3(23 \%) \\
4(30 \%) \\
3(23 \%)\end{array}$ \\
\hline $\begin{array}{l}\text { Type of imaging done } \\
\text { for assessment } \\
\text { Angiogram alone } \\
\text { MRA \& Angiogram }\end{array}$ & $\begin{array}{l}3(23 \%) \\
10(77 \%)\end{array}$ \\
\hline $\begin{array}{l}\text { Site of AVM } \\
\text { Frontoparietal } \\
\text { Thalamic } \\
\text { Temporal } \\
\text { Occipital } \\
\text { Basal ganglia } \\
\text { Corpus callosum } \\
\text { Vermian }\end{array}$ & $\begin{array}{l}4(30 \%) \\
2(15.4 \%) \\
2(15.4 \%) \\
1(7.7 \%) \\
1(7.7 \%) \\
2(15.4 \%) \\
1(7.7 \%)\end{array}$ \\
\hline $\begin{array}{l}\text { Location of AVM } \\
\text { Superficial } \\
\text { Deep }\end{array}$ & $\begin{array}{l}9(70 \%) \\
4(30 \%)\end{array}$ \\
\hline $\begin{array}{l}\text { Mean Spetzler-Martin gra } \\
\text { I } \\
\text { II } \\
\text { III }\end{array}$ & $\begin{array}{l}0 \\
5(38.5 \%) \\
8(61.5 \%)\end{array}$ \\
\hline $\begin{array}{l}\text { Treatment Characteristics } \\
\text { No. of beams for SRS } \\
\text { Nidus volume } \\
\text { Prescribed Dose } \\
\text { Follow up } \\
\text { Obliteration rate,Complete } \\
\text { Partial }\end{array}$ & $\begin{array}{l}9 \text { (Range: } 7-12) \\
2.32 \text { cc (Range: } 0.7-4) \\
21.7 \text { Gy (Range: } 15-22) \\
30 \text { months (Range: } 13-63) \\
9(70 \%) \\
4(30 \%)\end{array}$ \\
\hline
\end{tabular}

Abbreviations: $\mathrm{AVM}=$ Arteriovenous malformations, $\mathrm{cc}=$ cubic centimeters, $\mathrm{Gy}=\mathrm{Gray}$,

$\mathrm{SRS}=$ Stereotactic Radiosurgery.

Management of AVMs involves different modalities including neuroradiology, interventional radiology, neurosurgery and radiation oncology. The aim of treatment is to prevent bleeding and to achieve complete nidus obliteration without causing a new neurological deficit [10]. There are mainly four different strategies for treating AVMs: 1) microsurgical resection, 2) endovascular embolization, 3) Stereotactic radiosurgery and 4) the combination of the above methods. Although the total surgical resection of AVMs is regarded as a possible standard therapy, it is considered to be a high surgical risk associated with large AVMs or those located in eloquent areas of brain. Although SRS is one alternative that showed safety and efficacy in treating small AVMs, it has been reported to present a lower success rate in complete obliteration and also higher rate of complications when treating large AVMs. Endovascular embolization as an adjuvant therapy before microsurgery or radiosurgery is used sometimes to reduce nidus size and/or the elimination of vascular structures bearing an increased risk of hemorrhage. There is a lack of evidence from randomized trials to point out the role of each of the modalities in the treatment of the AVM [11,12].

The rates of morbidity and mortality were as low as $1.5 \%$ and $0 \%$ respectively in a series considering only microsurgical resection of small AVMs $(<3 \mathrm{~cm}$ in diameter). The chief advantage of surgery is that patient is cured instantly. However, the rate of serious morbidity may reach as high as $50 \%$ in large AVMs located in or adjacent to critical areas with deep extension. Such a morbidity rate is considered unacceptable and surgery in these cases should be considered only in carefully selected cases. Treatments with embolization, surgery or SRS carry a significant risk of complications. There is a controversy whether to treat AVMs and accept risk of any treatment or to observe and treat them only in the case of bleeding. Consensus exists in treating AVMs with a prior history of bleeding and the ones located in critical areas of brain with a higher probability of a neurological deficit even if asymptomatic while asymptomatic AVMs in "safe" regions are usually observed [9].

Within the last decades, radiosurgery has become increasingly popular as a non-invasive treatment of small benign tumors, arteriovenous malformations, some functional neurological structures, such as the fifth cranial nerve for trigeminal neuralgia and metastases. It allows delivering very high dose in a small volume precisely under stereotactic conditions with minimal irradiation of normal tissue around the area [13]. It was first used to treat cerebral AVMs in Sweden in the 1970s. Radiosurgery is believed to work by endothelial cell proliferation, progressive cell wall thickening and eventual luminal closure resulting in obliteration of AVM. As opposed to the alternative therapeutic procedures available for cerebral AVMs, surgical resection or embolization, this vasoocclusive effect develops slowly after radiosurgery, and cerebral AVMs shrink progressively. These vasoocclusive effects peak between 1 and 2 years after radiosurgery. The risk of bleeding is not modified by radiosurgery [13]. The postradiosurgical response of a cerebral AVM appears to be highly variable, because complete obliteration can be seen as early as a few months or late as 5 years after treatment, or may never occur by the end of the follow-up period. Different techniques have been used with similar results (obliteration rate varying between $60 \%$ to $86 \%$ after 2 years): proton beams, gamma units, heavy-charged particles, and linear accelerators [15].

The first equipment devoted to radiosurgery was the Leksell Gamma Knife ${ }^{\circledast}$. It is now challenged by some linear accelerators providing radiosurgery technology, such as the CyberKnife ${ }^{\circledast}$, the Novalis $\mathrm{Tx}^{\circledast}$ radiosurgery platform, BrainLab $^{\circledast}$ and the True Beam ${ }^{\circledast}$ linear accelerator [13]. Linear accelerator based stereotactic radiosurgery (SRS) is a single- 
Fareed et al. Neuroscience Discovery 2013,

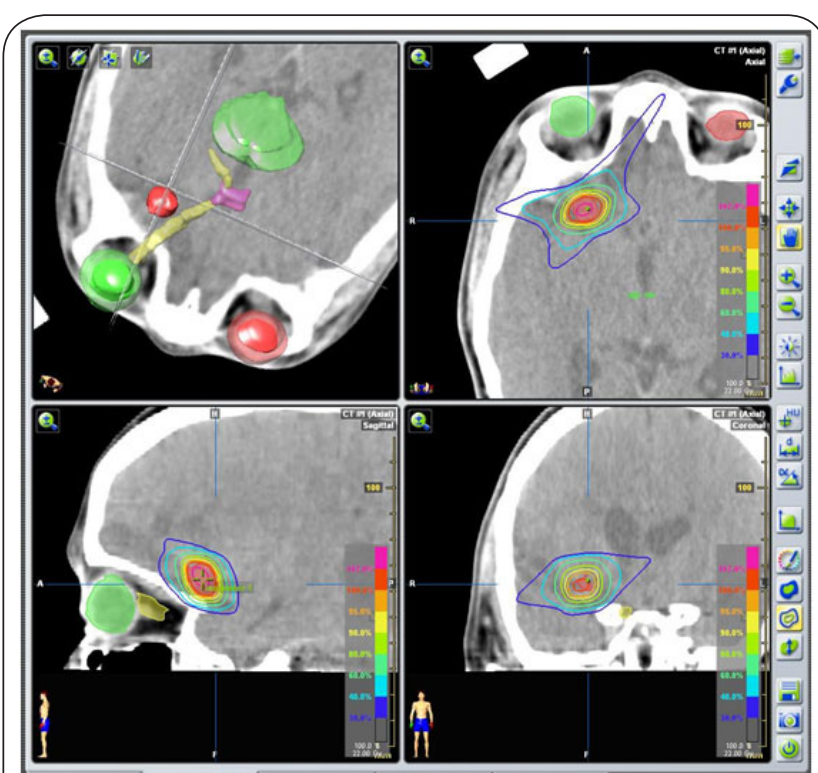

Figure 4. Axial, sagittal and coronal views showing isodose curves with $80 \%$ coverage shown by light green line.

fraction radiotherapeutic technique using a combination of a stereotactic apparatus and narrow multiple beams delivered through noncoplanar fields. LINAC based SRS with micromultileaf collimator (mMLC) has advantage over the standard cone-based system especially for mediumsized irregular targets in terms of physical, geometrical, and dosimetric considerations. Computer-controlled mMLC provides superior dose conformity by allowing flexible and efficient design of individually shaped static or dynamic fields thus taking the shape of a three-dimensional projection of irregular planning target volumes [9]. The overall obliteration index depends upon dose, volume and time and is about $80 \%$ with LINAC based radiosurgery. The isodose coverage curve for the AVM with LINAC based SRS is generally the one of the $80 \%$ (Figure 4) and the mean dose reported in the literature ranges between 15 and $25 \mathrm{~Gy}$. There can be a treatment failure defined as the necessity to retreat the patient after three years from the first radiosurgical treatment in about $26 \%$ of the patients. Surgically inaccessible AVM can be successfully treated using SRS with acceptable obliteration rates and low risk for late morbidity. The risk of intracranial hemorrhage depends on RS-based AVM score and is reduced after radiosurgery [16]. The rate of obliteration after RS in AVM depends on applied single dose, size of nidus and SpetzlerMartin grade. Especially in patients with small or surgically inaccessible AVMs, RS is an alternative to neurosurgery [10].

The superiority of BrainLab system was proved in a study by Scarbrough TJ et al., in which they treated 84 patients utilizing a linear accelerator-based patient rotator (PR) (45 pts) or BrainLab (BL) radiosurgery system (39 pts) (BrainLab AG, Heimstetten, Germany). BL-based radiosurgery achieved a high NO rate as compared to PR method. Differences in outcomes between PR/BL groups may be due to localization methods or an inherent advantage with the BL system [17]. It is worth mentioning that our study also utilized BrainLab radiosurgery planning system.

Appropriate selection of patients determines the success of SRS in arteriovenous malformations. An obliteration rate of AVMs is dependent upon the marginal dose delivered. However, treatment-induced symptomatic postradiosurgery sequelae also depend upon the dose delivered to the normal brain. Thus, a smaller nidus in noneloquent areas where higher dose can be delivered to the nidus has the highest probability of obliteration with minimum toxicity. Schlienger $\mathrm{M}$ et al., presented their data for Linac radiosurgery for AVM in 169 evaluable patients treated from January 1990 to December 1993. Higher values for the peripheral dose and isodose tended to give better results. It was shown by multivariate analysis that the absence of prior embolization and monoisocentric irradiation were independent factors predicting successful irradiation [18].

Optimal relationship of dose and volume to obliteration, hemorrhage and complications is not fully understood for radiosurgery of large arteriovenous malformations. Multivariate analysis was performed to assess the relationship of multiple AVM and treatment factors to the outcome of larger AVMs. Seventy three patients with intracranial AVMs underwent LINAC radiosurgery. It was shown that the dose-volume range for the optimal balance between successful obliteration and the risk of complications and post-radiosurgical hemorrhage narrows as the size of AVM increases [19].

Outcome of radiosurgery for cerebral AVMs is usually assessed with serial MRI after 6 months of completion of SRS and cerebral angiography at 1 year interval. With a marginal dose of $20-25 \mathrm{~Gy}$, the obliteration rate is between 80 and $100 \%$ in smaller AVMs ( $<3 \mathrm{~cm}$ diameter), morbidity rates are between 2 to $4 \%$, and the mortality rate between 0 to $1 \%$. However, the obliteration rate ranges from 30 to $60 \%$, in larger AVMs having diameter of more than $3 \mathrm{~cm}$, with a dose of 15-20 Gy and a long-term complication probability of $20-30 \%$. With a higher radiation dose (25-45 Gy), a higher obliteration rate could be obtained but with a higher complication rate ( $50 \%)$. The obliteration of the nidus is possible because of the late effect of radiation, hence there is a latency period of upto 2 years between SRS procedure and obliteration of the nidus. The rate of hemorrhage is identical to the natural history (3-4\% per year) during this period of latency before complete obliteration. Certain disadvantages associated with the procedure are that the obliteration of the malformation takes time with SRS, it is not always successful and carries a risk of hemorrhage during the period of latency. Late radiation-induced brain injury and the obliteration rate is entirely dependent upon proper selection of cases. There is mature data regarding both the obliteration rate and complication [9]. However, there are very few publications from Saudi Arabia regarding 
the outcome of AVMs treated with SRS. Since a prospective and elaborative analysis of AVMs treated with SRS is lacking from this part of the world, our report may well be among the first few detailing outcome data in this regard.

We are aware of the fact that our data are based on a relatively small number of patients. However, in this analyzed cohort all patients have shown an excellent response so far in terms of obliteration of AVM, tolerance to radiosurgery dose, and favorable toxicity profile. In our study, pre-embolization with Onyx does not affect the efficacy of SRS. Our initial experience has justified the multidisciplinary decision-making process and management approach along with robustness of the carefully defined pre- and posttreatment protocols. We intend to continue accruing patients on this protocol for more mature results in a larger patient population.

\section{Conclusions}

SRS is a viable and safe option in the management of small AVMs. Stringent case selection provides acceptable obliteration rates with minimal long-term toxicity. This study provides a platform for treating more patients having brain arteriovenous malformations with stereotactic radiosurgery technique. The choice of patients is critical depending mainly upon size of AVM and its location within the cranium. Obviously there is a need for collection of large database to fully explore the other prognostic and risk factors.

\section{List of abbreviations}

SRS: Stereotactic Radiosurgery

AVM: Arteriovenous Malformation

LINAC: Linear accelerator

MRI: Magnetic Resonance Imaging

MRA: Magnetic resonance angiogram

DSA: Digital subtraction Angiography

CT: Computed Tomogram

OAR: Organs at Risk

SD: Standard Deviation

mMLC: Micromultileaf Collimator

DVH: Dose Volume Histogram

NO: Nidus Obliteration

\section{Competing interests}

The authors declare that they have no competing interests.

\section{Authors' contributions}

AA prescribed the radiation dose and evaluated the plan before executing radiation treatment; $Y B$ contoured the AVM nidus and normal brain structures, $Y O$ carried out the stereotactic frame placement, MT participated in the design of the study and performed the statistical analysis. KR conceived the study, and participated in its design and coordination and helped to draft the manuscript. All authors read and approved the final manuscript.

\section{Acknowledgement}

We are thankful to Sultan Qahtani, Consultant Medical Imaging, King Fahad Medical City and Mohamed Abosaleh, Consultant Medical Physics, King Fahad Medical city for their logistic support in providing the data for embolization and treatment planning, respectively. We also owe our thanks for Dr Mahmoud Al Yamani for providing the necessary guidance and opinion regarding the overall structure building of this study.

Publication history

Received: 27-Feb-2013 Revised: 15-Apr-2013

Re-Revised: 19-Apr-2013 Accepted: 20-Apr-2013

Published: 25-Apr-2013

\section{References}

1. Wang HC, Chang RJ and Xiao F: Hypofractionated stereotactic radiotherapy for large arteriovenous malformations. Surg Neurol Int 2012, 3:S105-10. | Article | PubMed Abstract | PubMed Full Text

2. Ferrara AR: Brain arteriovenous malformations. Radiol Technol 2011, 82:543MR-56MR. I Article I PubMed

3. Barr JC and Ogilvy CS: Selection of treatment modalities or observation of arteriovenous malformations. Neurosurg Clin N Am 2012, 23:63-75. | Article | PubMed

4. Gross BA and Du R: Surgical and radiosurgical results of the treatment of cerebral arteriovenous malformations. J Clin Neurosci 2012, 19:1001-4. | Article | PubMed

5. See AP, Raza S, Tamargo RJ and Lim M: Stereotactic radiosurgery of cranial arteriovenous malformations and dural arteriovenous fistulas. Neurosurg Clin N Am 2012, 23:133-46. | Article | PubMed

6. Latorzeff I, Schlienger M, Sabatier J, Borius PY, Bourdin S, Menegalli D, Cognard C, Januel AC, Lotterie JA, Desal H, Debono B and Blond $\mathrm{S}$ : Radiosurgery for brain arteriovenous malformations. Cancer Radiother 2012, 16 Suppl:S46-56. | Article | PubMed

7. Blamek S, Tarnawski R and Miszczyk L: Linac-based stereotactic radiosurgery for brain arteriovenous malformations. Clin Oncol ( $R$ Coll Radiol) 2011, 23:525-31. I Article I PubMed

8. Zamzuri I, Badrisyah I, Rahman GI, Pal HK, Muzaimi M, Jafri AM, War M, Shafie AM, Ruzman NI, Biswal BM and Ahmad Z: LINAC based radiosurgery and radiotherapy for neurosurgical diseases: what have we learnt so far. Med J Malaysia 2011, 66:346-9. | Pdf | PubMed

9. Jalali R, Dutta D, Srinivas C, Munshi A, Limaye U, Goel A, Deshpande $D$ and Sarin R: Micromultileaf collimator-based stereotactic radiosurgery for selected arteriovenous malformations: technique and preliminary experience. J Cancer Res Ther 2009, 5:186-91. | Article | PubMed

10. Zabel A, Milker-Zabel S, Huber P, Schulz-Ertner D, Schlegel W and Debus J: Treatment outcome after linac-based radiosurgery in cerebral arteriovenous malformations: retrospective analysis of factors affecting obliteration. Radiother Oncol 2005, 77:105-10. | Article I PubMed

11. Moreno-Jimenez S, Celis-Lopez MA, Larraga-Gutierrez JM, HerreraGomez L, Suarez-Campos JJ, Garcia-Garduno A and HernandezBojorquez M: Intracranial arteriovenous malformations and radiosurgery with LINAC: review article. Neurocirugia (Astur) 2006, 17:317-23; discussion 324. | Article | PubMed

12. Arai $Y$, Handa $Y$, Ishii $H$, Ueda $Y$, Uno $H$, Nakajima T, Hirose $S$ and Kubota T: Endovascular therapy followed by stereotactic radiosurgery for cerebral arteriovenous malformations. Interv Neuroradiol 2006, 12:163-6. | PubMed Abstract | PubMed Full Text

13. Mazeron JJ, Valery CA, Boisserie G and Cornu P: History of radiosurgery. Cancer Radiother 2012, 16 Suppl:S2-4. | Article | PubMed

14. Varela-Rois $P$, Martinez-Cueto $P$, Lopez-Medina A, Caeiro-Munoz M, Salvador-Gomez F, Munoz-Garzon V and Otero-Vich JM: Haemorrhage in arteriovenous malformations of the brain following radiosurgery: the importance of the latency period. Rev Neurol 2008, 47:403-9. | Article | PubMed

15. Oppenheim C, Meder JF, Trystram D, Nataf F, Godon-Hardy S, Blustajn J, Merienne L, Schlienger M and Fredy D: Radiosurgery of cerebral arteriovenous malformations: is an early angiogram needed? AJNR Am J Neuroradiol 1999, 20:475-81. I Article I PubMed

16. Zabel-du Bois A, Milker-Zabel S, Huber P, Schlegel W and Debus J: Stereotactic linac-based radiosurgery in the treatment of cerebral 
Fareed et al. Neuroscience Discovery 2013,

http://www.hoajonline.com/journals/pdf/2052-6946-1-1.pdf

arteriovenous malformations located deep, involving corpus callosum, motor cortex, or brainstem. Int J Radiat Oncol Biol Phys 2006, 64:1044-8. | Article | PubMed

17. Scarbrough TJ, Crocker IR, Davis LW, Barrow DL, Fowler BZ and Oyesiku NM: Intracranial arteriovenous malformations treated utilizing a linear accelerator-based patient rotator or commercially available radiosurgery system. Stereotact Funct Neurosurg 2005, 83:91-100. | Article I PubMed

18. Schlienger M, Atlan D, Lefkopoulos D, Merienne L, Touboul E, Missir O, Nataf F, Mammar H, Platoni K, Grandjean P, Foulquier JN, Huart J, Oppenheim C, Meder JF, Houdart E and Merland JJ: Linac radiosurgery for cerebral arteriovenous malformations: results in 169 patients. Int J Radiat Oncol Biol Phys 2000, 46:1135-42. I Article | PubMed

19. Miyawaki L, Dowd C, Wara W, Goldsmith B, Albright N, Gutin P, Halbach V, Hieshima G, Higashida R, Lulu B, Pitts L, Schell M, Smith $\mathrm{V}$, Weaver K, Wilson C and Larson D: Five year results of LINAC radiosurgery for arteriovenous malformations: outcome for large AVMS. Int J Radiat Oncol Biol Phys 1999, 44:1089-106. | Article | PubMed

\section{Citation:}

Fareed MM, Amro AA, Bayoumi Y, Orz YI, Tunio M, Maklad A and Riaz K: LINAC Stereotactic Radiosurgery for brain arteriovenous malformation: a single institutional experience from Saudi Arabia. Neuroscience Discovery 2013, 1:1.

http://dx.doi.org/10.7243/2052-6946-1-1 